\title{
A Charged Residue in S4 Regulates Coupling among the Activation Gate, Voltage, and $\mathrm{Ca}^{2+}$ Sensors in BK Channels
}

\author{
Guohui Zhang, ${ }^{1,2}$ Huanghe Yang, ${ }^{3}$ Hongwu Liang, ${ }^{1}$ Junqiu Yang, ${ }^{1}$ Jingyi Shi, ${ }^{1}$ Kelli McFarland, ${ }^{1}$ Yihan Chen, ${ }^{4}$ \\ and Jianmin $\mathrm{Cui}^{1,2}$ \\ ${ }^{1}$ Department of Biomedical Engineering, Center for the Investigation of Membrane Excitability Disorders, Cardiac Bioelectricity and Arrhythmia Center, \\ Washington University, St. Louis, Missouri 63130, ${ }^{2}$ Department of Pharmacology, Soochow University College of Pharmaceutical Sciences, Suzhou 215123 , \\ China, ${ }^{3}$ Department of Physiology, University of California at San Francisco, San Francisco, California 94143, and ${ }^{4}$ Key Laboratory of Basic Research in \\ Cardiology of the Ministry of Education of China (Tongii University), Shanghai 200120, China
}

Coupling between the activation gate and sensors of physiological stimuli during ion channel activation is an important, but not wellunderstood, molecular process. One difficulty in studying sensor-gate coupling is to distinguish whether a structural perturbation alters the function of the sensor, the gate, or their coupling. BK channels are activated by membrane voltage and intracellular $\mathrm{Ca}^{2+}$ via allosteric mechanisms with coupling among the activation gate and sensors quantitatively defined, providing an excellent model system for studying sensorgate coupling. By studying BK channels expressed in Xenopus oocytes, here we show that mutation E219R in S4 alters channel function by two independent mechanisms: one is to change voltage sensor activation, shifting voltage dependence, and increase valence of gating charge movements; the other is to regulate coupling among the activation gate, voltage sensor, and $\mathrm{Ca}^{2+}$ binding via electrostatic interactions with $\mathrm{E} 321 / \mathrm{E} 324$ located in the cytosolic side of S6 in a neighboring subunit, resulting in a shift of the voltage dependence of channel opening and increased $\mathrm{Ca}^{2+}$ sensitivity. These results suggest a structural arrangement of the inner pore of BK channels differing from that in other voltage gated channels.

Key words: BK channels; coupling; intersubunit interaction; pore-gate; voltage sensor

\section{Introduction}

Many ion channels contain distinct structural domains that function as the sensor of physiological stimuli and the pore that allows ions to flow across the membrane. The opening of these ion channels includes three general molecular processes: activation of the sensor, propagation of the conformational changes in the sensor to the pore, and the opening of the pore. Although the activation of sensors and the opening of the pore have been extensively studied in voltage gated $\mathrm{K}^{+}(\mathrm{Kv})$ channels (Yellen, 1998; Bezanilla, 2005), the process of the coupling between the sensor and the pore is still not well understood.

BK channels activate by sensing the membrane voltage and intracellular $\mathrm{Ca}^{2+}$ (Cui et al., 2009) and are important to neuronal excitability (Lancaster and Nicoll, 1987; Storm, 1987), neurotransmitter release (Robitaille et al., 1993), and muscle contraction (Brayden and Nelson, 1992). Similar to Kv channels, the BK channels are homotetramers with the central pore formed by S5 to S6 transmembrane segments from all four subunits and voltage sensor

\footnotetext{
Received March 24, 2014; revised July 27, 2014; accepted July 30, 2014

Author contributions: G.Z., Y.C., and J.C. designed research; G.Z., H.Y., H.L., J.Y., J.S., and K.M. performed research; G.Z. contributed unpublished reagents/analytic tools; G.Z. analyzed data; G.Z. and J.C. wrote the paper.

This work was supported by National Institutes of Health Grants R01-HL70393 and R01-NS060706 and National Science Foundation of China Grant 31271143 to J.C., as well as Major International Joint Research Program Fund of China 81120108004 to Y.C. and J.C.

The authors declare no competing financial interests.

Correspondence should be addressed to Dr. Jianmin Cui, Department of Biomedical Engineering, Center for the Investigation of Membrane Excitability Disorders, Cardiac Bioelectricity and Arrhythmia Center, Washington University, St. Louis, M0 63130. E-mail: jcui@wustl.edu.

DOI:10.1523/JNEUROSCI.1174-14.2014

Copyright $\odot 2014$ the authors $\quad 0270-6474 / 14 / 3412280-09 \$ 15.00 / 0$
}

domains (VSDs) containing S1-S4 transmembrane segments. A cytosolic S4-S5 linker covalently links the VSD to the pore. BK channels also contain a cytosolic gating ring formed by RCK1 and RCK2 domains from four subunits (Wu et al., 2010; Yuan et al., 2010, 2011). Two $\mathrm{Ca}^{2+}$ binding sites have been identified in the gating ring: one in RCK1 (Shi et al., 2002; Xia et al., 2002; Zhang et al., 2010) and the other, $\mathrm{Ca}^{2+}$ Bowl, in RCK2 (Schreiber and Salkoff, 1997; Yuan et al., 2010). A peptide linker (C-Linker) links S6 to the gating ring. The voltage sensor activation, $\mathrm{Ca}^{2+}$ binding, the opening of the activation gate, and the coupling among these molecular processes are quantitatively described by an allosteric model (Horrigan and Aldrich, 2002). A landmark study showed that the C-Linker is important for the coupling between $\mathrm{Ca}^{2+}$ binding and channel opening (Niu et al., 2004). It is proposed that a change of the gating ring conformation upon $\mathrm{Ca}^{2+}$ binding to the $\mathrm{Ca}^{2+}$ Bowl may pull channel open through the C-Linker (Yuan et al., 2010). However, how the C-Linker connects the pore and the gating ring or how S6 move in response to the gating ring conformational change is not known. The coupling between the VSD and activation gate has not been studied.

In this study, we show that electrostatic interactions between E219 in S4 and E321/E324 in the C-Linker modulate the coupling among the activation gate, voltage, and $\mathrm{Ca}^{2+}$ sensors. Mutation E219R reduces the coupling of the activation gate with the voltage sensor but enhances the coupling to $\mathrm{Ca}^{2+}$ binding. These effects on coupling are independent from the changes in the activation of the voltage sensor. The results provide insights on the molecular mechanisms of sensor-gate coupling in BK channels that may modify previous hypotheses and suggest an inner pore structure that differs from other $\mathrm{Kv}$ channels. 


\section{Materials and Methods}

Mutagenesis and expression. We made mutations using overlap-extension PCR with Pfu polymerase (Stratagene) from the mbr5 splice variant of mslo1 (Butler et al., 1993). The PCR-amplified regions were verified by sequencing (Shi et al., 2002). RNA was transcribed in vitro with T3 polymerase (Ambion) and injected into oocytes (Stage IV-V) from female Xenopus laevis with an amount of $0.05-50$ or 150-250 ng/oocyte for recording ionic and gating currents, respectively, followed by $2-7 \mathrm{~d}$ of incubation at $18^{\circ} \mathrm{C}$.

Electrophysiology. Ionic currents were recorded with inside-out patches using an Axopatch 200-B patch-clamp amplifier (Molecular Devices) and Pulse acquisition software (HEKA Electronik). Inside-out patches were formed from oocyte membrane by borosilicate pipettes of $0.8-1.5 \mathrm{M} \Omega$ resistance. The current signals were low-pass-filtered at $10 \mathrm{kHz}$ with the amplifier's four-pole Bessel filter and digitized at $20 \mu$ s intervals. Capacitive transients and leak currents were subtracted using a $\mathrm{P} / 4$ protocol with a holding potential of $-120 \mathrm{mV}$. Our pipette solution contains (in $\mathrm{mM}$ ) the following: 140 potassium methanesulphonic acid, $20 \mathrm{HEPES}, 2 \mathrm{KCl}, 2$ $\mathrm{MgCl}_{2}$, $\mathrm{pH}$ 7.2. The nominal $0 \mu \mathrm{M}\left[\mathrm{Ca}^{2+}\right]_{\mathrm{i}}$ solution contains (in mM) the following: 140 potassium methanesulphonic acid, $20 \mathrm{HEPES}, 2 \mathrm{KCl}, 5$ EGTA, and $22 \mathrm{mg} / \mathrm{L}(+)-18$-crown-6-tetracarboxylic acid (18C6TA), $\mathrm{pH}$ 7.2. The free $\left[\mathrm{Ca}^{2+}\right]_{\mathrm{i}}$ in the nominal $0\left[\mathrm{Ca}^{2+}\right]_{\mathrm{i}}$ solution is $\sim 0.5 \mathrm{~nm}$. Different $\left[\mathrm{Ca}^{2+}\right]_{\mathrm{i}}$ solutions were made by adding $\mathrm{CaCl}_{2}$ in a basal solution containing (in mM) the following: 140 potassium methanesulphonic acid, 20 HEPES, 2 $\mathrm{KCl}, 1$ EGTA, and $22 \mathrm{mg} / \mathrm{L}$ 18C6TA, pH 7.2, to obtain the desired free $\left[\mathrm{Ca}^{2+}\right]_{\mathrm{i}}$, which was measured by a $\mathrm{Ca}^{2+}$-sensitive electrode (Thermo Electron). We recorded gating currents also with inside-out patches, and currents were filtered at $20 \mathrm{kHz}$, sampled at $200 \mathrm{kHz}$, and leak subtracted using $\mathrm{a}-\mathrm{P} / 4$ protocol. The pipette solution contained (in $\mathrm{mM}$ ) the following: 127 tetraethylammonium (TEA) hydroxide, 125 methanesulfonic acid, $2 \mathrm{HCl}, 2$

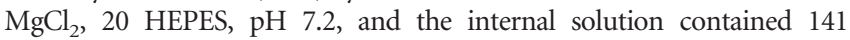
$N$-methyl-D-glucamine (NMDG), 135 methanesulfonic acid, $6 \mathrm{HCl}, 20$ HEPES, 5 EGTA, pH 7.2. All chemicals were obtained from Sigma-Aldrich unless otherwise noted, and all the experiments were performed at room temperature $\left(22^{\circ} \mathrm{C}-24^{\circ} \mathrm{C}\right)$.

Analysis. Relative conductance was determined by measuring macroscopic tail current amplitudes at $-80 \mathrm{mV}$. The G-V curves were fitted with the Boltzmann function as follows:

$$
G / G_{\max }=1 /\left(1+\exp \left(-z e\left(V-V_{1 / 2}\right) / k T\right)\right)=1 /\left(1+\exp \left(\left(\mathrm{V}_{1 / 2}-V\right) / b\right)\right)
$$

where $G / G_{\max }$ is the ratio of conductance to maximal conductance, $z$ is the number of equivalent charges, $e$ is the elementary charge, $V$ is membrane potential, $V_{1 / 2}$ is the voltage where $G / G_{\max }$ reaches $0.5, k$ is Boltzmann's constant, $T$ is absolute temperature, and $b$ is slope factor $(\mathrm{mV})$. Each G-V curve was obtained from 3 to 15 patches; in all the figures, error bars indicate SEM.

Model fitting. $\mathrm{P}_{\mathrm{o}}-\mathrm{V}$ curves of the wild-type (WT) and E219R channels at 0 $\left[\mathrm{Ca}^{2+}\right]_{\mathrm{i}}$ were first fitted with the HCA model (Horrigan et al., 1999)

$$
P_{o}=L(1+J D)^{4} /\left(L(1+J D)^{4}+(1+J)^{4}\right)
$$

where:

$$
\begin{gathered}
L(V)=L_{0 \exp }\left(-Z_{L} V / K T\right) \\
J(V)=J_{0 \exp }\left(-Z_{J} V / K T\right)=\exp \left(\left(V-V_{h}\right) Z_{J} V / K T\right)
\end{gathered}
$$

These fittings provide the value for parameters $V_{h}, Z_{F}, Z_{L}, L_{0}$, and $D$ factor for both WT and mutation E219R channels.

G-V relationships for both WT and mutation E219R in different intracellular $\left[\mathrm{Ca}^{2+}\right]_{\mathrm{i}}, 0,1,2,5,10,30$, and $100 \mu \mathrm{M}$, were then fitted to the HA model (Eq. 5) (Horrigan and Aldrich, 2002) with $V_{h}, Z_{J}, Z_{L}, L_{O}$, and $D$ factor fixed and allowing $K_{D}$, $C$, and $E$ factors to vary freely. These fittings provide values for parameters $K_{D}, C$, and $E$ factors.

$$
P o=L(1+K C+J D+J K C D E)^{4} /\left(L(1+K C+J D+J K C D E)^{4}\right.
$$

$$
\left.+(1+K+J+J K E)^{4}\right)
$$

where:

$$
K=\left[C a^{2+}\right]_{\mathrm{i}} / K_{D}
$$

\section{Results}

\section{Mutation E219R changes voltage and $\mathrm{Ca}^{2+}$-dependent activation}

Mutation scans of S4 and the S4-S5 linker in previous studies showed that mutations of E219 alter voltage and $\mathrm{Mg}^{2+}$. dependent activation of mSlo1 channels (Hu et al., 2003). We measured gating currents of the WT and E219R mSlo1 at 0 $\left[\mathrm{Ca}^{2+}\right]_{\mathrm{i}}($ Fig. $1 \mathrm{~A}$ ) and found that the mutation shifted the voltage dependence of gating charge movement $(\mathrm{Q}-\mathrm{V})$ to more negative voltages by $-126 \mathrm{mV}$ and increased the steepness of the Q-V relation by changing the slope factor of Boltzmann fits from 50 to $38 \mathrm{mV}$, which can be caused by an increase of gating charge (Fig. $1 B)$. These results indicated that E219R altered voltage sensor movements, consistent with previous findings that the mutation alters voltage-dependent gating. However, the shift of Q-V caused by the mutation was opposite to that of the voltage dependence of channel openings $(\mathrm{G}-\mathrm{V})$ at $0\left[\mathrm{Ca}^{2+}\right]_{\mathrm{i}}$, which was to more positive voltages by $93 \mathrm{mV}$ (Fig. $1 C, D$ ), suggesting that the mutation altered channel gating through mechanisms in addition to the changes in voltage sensor movements.

E219R also changed $\mathrm{Ca}^{2+}$-dependent activation. In response to the increase of $\left[\mathrm{Ca}^{2+}\right]_{\mathrm{i}}$ from 0 to $100 \mu \mathrm{M}$, the $\mathrm{G}-\mathrm{V}$ relation of both the WT and mutant mSlol channels shifted to more negative voltages, but the shift as measured by the voltage at halfmaximum activation, $\Delta \mathrm{V}_{1 / 2}$, was increased by the mutation from $-185 \mathrm{mV}$ to $-319 \mathrm{mV}$ (Fig. $1 D$ ). Such a change in $\mathrm{Ca}^{2+}$ sensitivity is equivalent to a change of free energy of channel opening in response to $\mathrm{Ca}^{2+}$ binding, $\Delta \mathrm{G}=\Delta\left(\mathrm{zV}_{1 / 2}\right)$, where $z$ is the number of gating charge proportional to the slope of the G-V relation. Comparing to $\Delta \mathrm{G}$ of $\mathrm{WT}\left(-23 \mathrm{KJmol}^{-1}\right)$ as $\left[\mathrm{Ca}^{2+}\right]_{\mathrm{i}}$ increases from 0 to $100 \mu \mathrm{M}, \Delta \mathrm{G}$ of E219R increased to -35 $\mathrm{KJmol}^{-1}$. The increase of $\mathrm{Ca}^{2+}$-dependent activation by E219R was also shown by the measurements of channel opening at low voltages where voltage sensor movements do not affect the open probability of intrinsic pore opening (Horrigan et al., 1999; Cui and Aldrich, 2000). The open probabilities of channels measured by single-channel activities (Fig. $1 E$ ) at low voltages, known as the limiting slope measurement (Horrigan et al., 1999; Cui and Aldrich, 2000), showed that E219R enhanced the open probability change in response to a $\left[\mathrm{Ca}^{2+}\right]_{\mathrm{i}}$ increase from 0 to $100 \mu \mathrm{M}$, equivalent to an enhancement of free energy of channel opening from $\Delta \mathrm{G}=-17 \mathrm{KJmol}^{-1}$ (WT) to $\Delta \mathrm{G}=-29 \mathrm{KJmol}^{-1}$ (E219R) (Fig. $1 F)$. Thus, $\mathrm{Ca}^{2+}$ sensitivities measured from both $\mathrm{G}-\mathrm{V}$ relationship and limiting slope showed that mutation E219R increased $\mathrm{Ca}^{2+}$ sensitivity by $>50 \%$. We noticed that mutation E219R also decreased intrinsic channel opening at $0 \mathrm{Ca}^{2+}$ (Fig. $\left.1 F\right)$.

Previous studies have identified two high-affinity $\mathrm{Ca}^{2+}$ binding sites in BK channels: one site located in the RCK1 domain, including residues D367 and E535 (Xia et al., 2002; Zhang et al., 2010) and the other, $\mathrm{Ca}^{2+}$ bowl, in the RCK2 domain (Schreiber and Salkoff, 1997; Bao et al., 2004; Yuan et al., 2010). To examine which site the $\mathrm{Ca}^{2+}$ sensitivity increase by E219R derives from, E219R was combined with mutations that abolished the function of $\mathrm{Ca}^{2+}$ binding sites in RCK1 (D367A, E535A), $\mathrm{Ca}^{2+}$ bowl (5D5N), and both sites (D367A/5D5N), respectively. E219R enhanced $\mathrm{Ca}^{2+}$ sensitivity with the same proportion as in the WT mSlol when the function of either $\mathrm{Ca}^{2+}$ binding site was abolished (Table 1), suggesting that the $\mathrm{Ca}^{2+}$ sensitivity increase derived from both $\mathrm{Ca}^{2+}$ binding sites. Because separate mechanisms underlay voltage and $\mathrm{Ca}^{2+}$-dependent activation of $\mathrm{BK}$ channels (Cui et al., 2009), the results that E219R enhanced $\mathrm{Ca}^{2+}$ 
sensitivity further suggest that the mutation altered channel gating through mechanisms that were fundamental for both voltage and $\mathrm{Ca}^{2+}$-dependent activation in addition to the changes in voltage sensor movements.

\section{Mutation E219R changes channel gating via electrostatic interactions with E321 and E324}

To study the mechanism of how E219R changes both voltage and $\mathrm{Ca}^{2+}$-dependent activation of BK channels, we examined whether electrostatic interaction was important. At first, E219 was mutated to different amino acids varying in size and charge, and G-V relationship at 0 and 100 $\mu \mathrm{M}\left[\mathrm{Ca}^{2+}\right]_{\mathrm{i}}$ were measured to obtain $\mathrm{V}_{1 / 2}$ at $0\left[\mathrm{Ca}^{2+}\right]_{\mathrm{i}}$ and $\mathrm{Ca}^{2+}$ sensitivity $\left(\Delta \mathrm{V}_{1 / 2}\right)$ of these mutant channels (Fig. $2 A$ ). All the E219 mutations either shifted G-V relation to more positive voltages at 0 $\left[\mathrm{Ca}^{2+}\right]_{\mathrm{i}}$, enhanced $\mathrm{Ca}^{2+}$ sensitivity, or both; however, the charge reversal mutations (E219R, E219K) altered these properties more than neutralizing mutations (E219A, E219C, and E219Q) (Fig. 2A). These results suggested that the mutations altered channel gating via changes in an electrostatic interaction involving E219. To further examine the importance of electrostatic interaction, we increased ionic strength of the intracellular solution by adding $1 \mathrm{M} \mathrm{NaCl}$. The increased ionic strength decreased $\mathrm{Ca}^{2+}$ sensitivity $\left(\Delta \mathrm{V}_{1 / 2}\right)$ of both the WT and E219R channels as $\left[\mathrm{Ca}^{2+}\right]_{\mathrm{i}}$ increased from 0 to $300 \mu \mathrm{M}$, from 277 to 263 $\mathrm{mV}$ for WT and from 350 to $263 \mathrm{mV}$ for E219R (Fig. 2B), consistent with the idea that $\mathrm{Ca}^{2+}$-dependent activation involved electrostatic interactions and E219R altered channel gating by change of an electrostatic interaction.

BK channels contain a large intracellu-

lar gating ring (Wu et al., 2010; Yuan et al., 2010, 2011), which is located close to the membrane spanning VSD formed by S1-S4 transmembrane segments and the pore-gate domain (PGD) formed by S5-S6 (Yang et al., 2007, 2008; Wang and Sigworth, 2009). E219 is located in the cytosolic end of S4 so that it may interact with charged residues located at the interface between the membrane spanning domains and the gating ring. To identify such residues, we performed a mutation scan on the background of E219R of charged residues in the linker between S6 and the gating ring (C-Linker) and the region in the gating ring that faces the membrane (Wu et al., 2010; Yuan et al., 2010, 2011). The results showed that the mutation of Glu321 and Glu324 reduced and the combined mutations E321A/E324A abolished the E219R effect on increase of $\mathrm{Ca}^{2+}$ sensitivity (Figs. $1 D$ and $3 A$ ). On the other hand, the mutations of other charged residues, including R329, K330, K331, R342, K343, E386, K392, R393, H394, and $\mathrm{H} 409$, did not prevent E219R from enhancing $\mathrm{Ca}^{2+}$ sensitivity (Figs. $1 D$ and $3 B$; data not shown). These results suggested that E219R interacted with E321 and E324. The limiting slope mea-
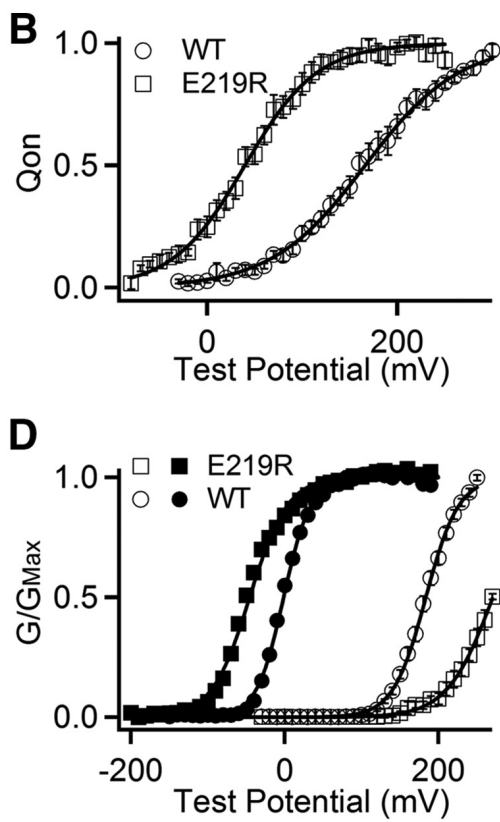

$\mathbf{F}$

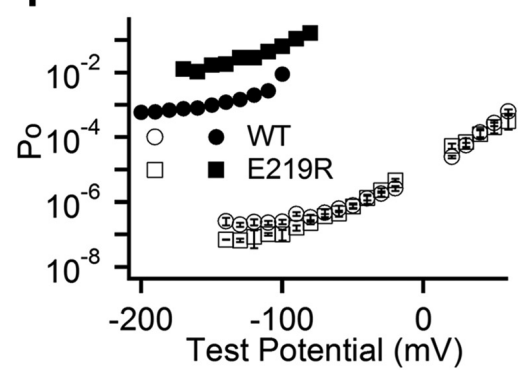

Figure 1. Mutation E219R changes voltage and $\mathrm{Ca}^{2+}$-dependent activation of $\mathrm{mSl} 101 \mathrm{BK}$ channels. $\boldsymbol{A}$, Gating current traces for WT and E219R mutation channels in $0\left[\mathrm{Ca}^{2+}\right]_{\mathrm{i}}$. Voltage pulses were from -30 to $300 \mathrm{mV}$ (WT) or from -80 to $250 \mathrm{mV}$ (E219R) at

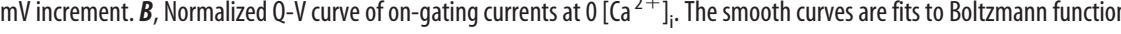
$\left[\mathrm{Ca}^{2+}\right]_{\mathrm{i}}$ (filled symbols). Solid lines indicate fits to Boltzmann relation with $\mathrm{V}_{1 / 2}$ and slope factor for WT: $184.0 \mathrm{mV}$ and $20.11 \mathrm{mV}$ at $0\left[\mathrm{Ca}^{2+}\right]_{\mathrm{i}}$, and $-1.8 \mathrm{mV}$ and $17.63 \mathrm{mV}$ at $100 \mu \mathrm{m}\left[\mathrm{Ca}^{2+}\right]_{\mathrm{i}}$; for E219R: $267.9 \mathrm{mV}$ and $25.58 \mathrm{mV}$ at $0\left[\mathrm{Ca}^{2+}\right]_{\mathrm{i}}$, and $-51.5 \mathrm{mV}$ and $24.73 \mathrm{mV}$ at $100 \mu \mathrm{m}\left[\mathrm{Ca}^{2+}\right]_{\mathrm{i}}$. $\boldsymbol{E}$, Current traces at $-140 \mathrm{mV} . \boldsymbol{F}$, Po-V relations at very negative voltages in 0 (open symbols) and 100 $\mu \mathrm{M}\left[\mathrm{Ca}^{2+}\right]_{\mathrm{i}}$ (filled symbols). Data points represent the mean $\pm \mathrm{SEM} ; n \geq 4$ for all figures unless specified otherwise.

Table 1. E219R enhances $\mathrm{Ca}^{2+}$ sensitivity derived from both $\mathrm{Ca}^{2+}$ binding sites

\begin{tabular}{lclll}
\hline Construct & $\Delta \mathrm{V}_{1 / 2}(\mathrm{mv})$ & Construct & $\Delta \mathrm{V}_{1 / 2}(\mathrm{mv})$ & Ratio \\
\hline WT & 190.0 & E219R & 318.1 & 1.67 \\
D367A & 69.9 & E219R/D367A & 127.9 & 1.83 \\
E535A & 80.2 & E219R/E535A & 126.5 & 1.58 \\
5D5N & 124.7 & E219R/5D5N & 203.5 & 1.63 \\
D367A/5D5N & 12.0 & E219R/D367A/5D5N & 18.5 & 1.54 \\
\hline
\end{tabular}

surement also showed that E321A/E324A eliminated the effect of E219 on $\mathrm{Ca}^{2+}$ sensitivity when VSD stays at the resting state (Fig. $3 C)$.

The E321A/E324A also reduced the effects of E219R on G-V shift at $0\left[\mathrm{Ca}^{2+}\right]_{\mathrm{i}}$ (Fig. 3A). However, E219R still shifted the Q-V relationship on the background of E321A/E324A by $-132 \mathrm{mV}$ (Fig. 3D), comparable with that in the WT background of -157 $\mathrm{mV}$ (Fig. $1 B$ ). These results suggested that, although E219R altered voltage sensor movements, the electrostatic interaction between E219R and E321 and E324 was primarily responsible for 


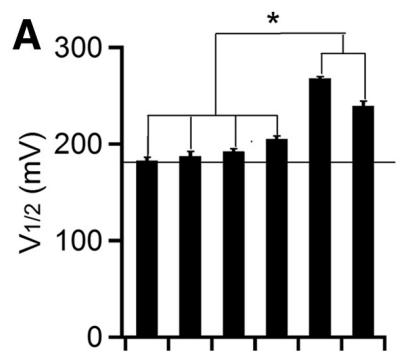

B WT with/without $1 \mathrm{M} \mathrm{NaCl}$
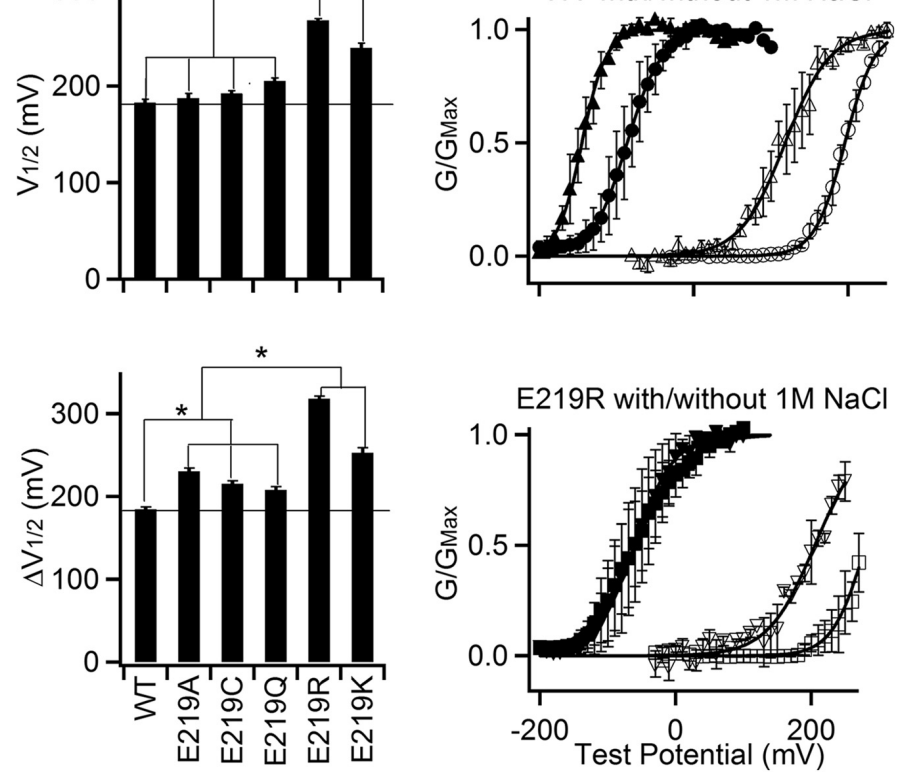

Figure 2. Mutation E219R changes channel function via electrostatic interactions. $A, E 219$ was mutated to various amino acids, and $\mathrm{G}-\mathrm{V}$ relations at 0 and $100 \mu \mathrm{m}\left[\mathrm{Ca}^{2+}\right]_{\mathrm{i}}$ were measured. Top, $\mathrm{V}_{1 / 2}$ of $\mathrm{G}-\mathrm{V}$ relations at $0\left[\mathrm{Ca}^{2+}\right]_{\mathrm{i}}$. Bottom, $\Delta \mathrm{V}_{1 / 2}=\mathrm{V}_{1 / 2}$ at 0 $\left[\mathrm{Ca}^{2+}\right]_{\mathrm{i}}-\mathrm{V}_{1 / 2}$ at $100 \mu \mathrm{m}\left[\mathrm{Ca}^{2+}\right]_{\mathrm{i}}{ }^{*}$ Significantly different $(p<0.05)$, Tukey-Kramer ANOVA test. $\boldsymbol{B}, \mathrm{G}-\mathrm{V}$ relationships in the absence (circle) or presence (triangle) of $1 \mathrm{~m} \mathrm{NaCl}$ in 0 (open symbols) and $300 \mu \mathrm{m}\left[\mathrm{Ca}^{2+}\right]_{\mathrm{i}}$ (filled symbols). Top, WT channels. Bottom, E219R. Solid lines indicate fits to Boltzmann relation with $\mathrm{V}_{1 / 2}$ and slope factor for WT: $195.5 \mathrm{mV}$ and $19.52 \mathrm{mV}$ at 0 $\left[\mathrm{Ca}^{2+}\right]_{i}$, and $-86.4 \mathrm{mV}$ and $22.60 \mathrm{mV}$ at $300 \mu \mathrm{m}\left[\mathrm{Ca}^{2+}\right]_{i}$ without the presence of $\mathrm{NaCl} ; 118.1 \mathrm{mV}$ and $29.12 \mathrm{mV}$ at $0\left[\mathrm{Ca}^{2+}\right]_{i}$, and $-144.9 \mathrm{mV}$ and $15.68 \mathrm{mV}$ at $300 \mu \mathrm{m}\left[\mathrm{Ca}^{2+}\right]_{\mathrm{i}}$ in $1 \mathrm{~m}[\mathrm{NaCl}]$; for E219R: $280.1 \mathrm{mV}$ and $24.61 \mathrm{mV}$ at $0\left[\mathrm{Ca}^{2+}\right]_{j}$, and $-59.8 \mathrm{mV}$ and $37.36 \mathrm{mV}$ at $300 \mu \mathrm{m}\left[\mathrm{Ca}^{2+}\right]_{i}$ without the presence of $\mathrm{NaCl} ; 205.1 \mathrm{mV}$ and $34.81 \mathrm{mV}$ at $0\left[\mathrm{Ca}^{2+}\right]_{i}$ and $-60.5 \mathrm{mV}$ and $28.75 \mathrm{mV}$ at $300 \mu \mathrm{M}\left[\mathrm{Ca}^{2+}\right]_{\mathrm{i}}$ in $1 \mathrm{~m}[\mathrm{NaCl}]$.
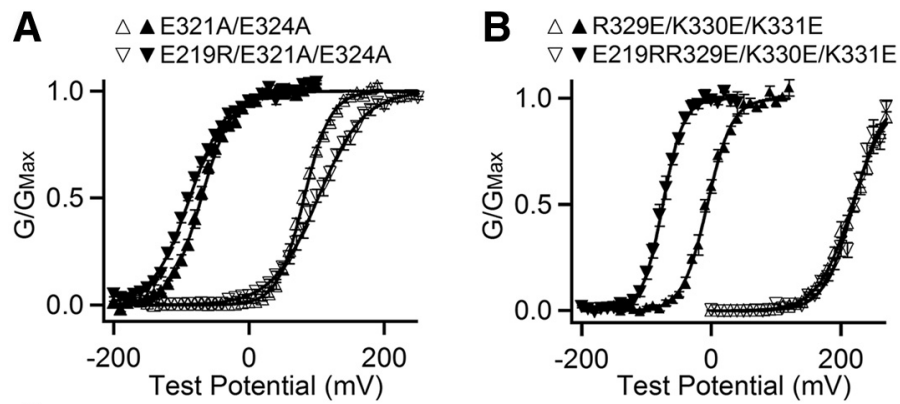

C

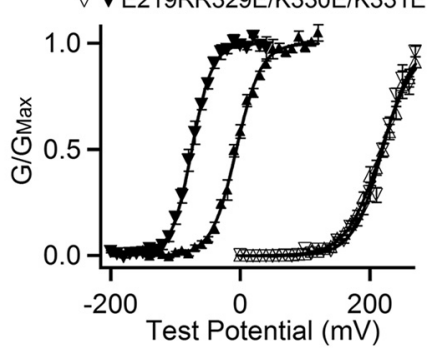

D
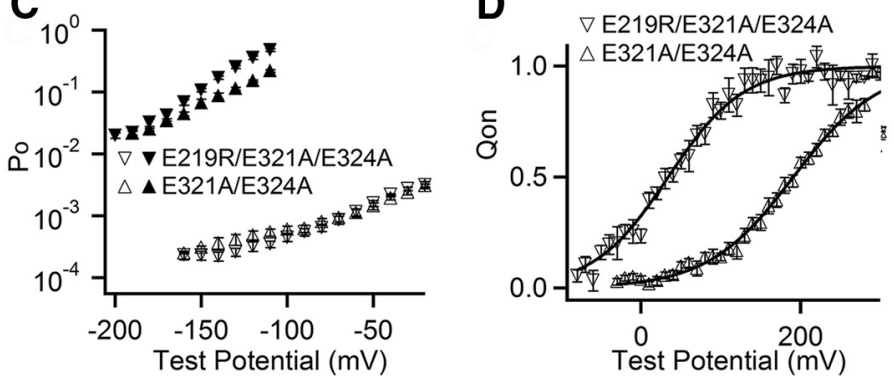

Figure 3. E219 interacts with E321 and E324. A, B, G-V relationship at 0 (open symbols) and $100 \mu \mathrm{M}$ (filled symbols) $\left[\mathrm{Ca}^{2+}\right]_{\mathrm{i}}$ and fits to Boltzmann function (smooth curves). $\boldsymbol{A}, \mathrm{V}_{1 / 2}$ and slope factor for E321A/E324A (triangle): $81.3 \mathrm{mV}$ and $19.54 \mathrm{mV}$ at 0 $\left[\mathrm{Ca}^{2+}\right]_{i ;}-70.8 \mathrm{mV}$ and $22.78 \mathrm{mV}$ at $100\left[\mathrm{Ca}^{2+}\right]_{i j}$; for E219R/E321A/E324A (inverted triangle): $102.2 \mathrm{mV}$ and $33.32 \mathrm{mV}$ at 0 $\left[\mathrm{Ca}^{2+}\right]_{\mathrm{i} ;} ;-87.4 \mathrm{mV}$ and $27.70 \mathrm{mV}$ at $100\left[\mathrm{Ca}^{2+}\right]_{\mathrm{i},}, \boldsymbol{B}, \mathrm{V}_{1 / 2}$ and slope factor for $\mathrm{R3} 29 \mathrm{~A} / \mathrm{K} 330 \mathrm{~A} / \mathrm{K} 331 \mathrm{~A}$ (triangle): $217.3 \mathrm{mV}$ and 26.50 $\mathrm{mV}$ at $0\left[\mathrm{Ca}^{2+}\right]_{;} ;-6.5 \mathrm{mV}$ and $19.13 \mathrm{mV}$ at $100\left[\mathrm{Ca}^{2+}\right]_{;}$; for E219R/R329A/K330A/K331A (inverted triangle): $219.2 \mathrm{mV}$ and 22.80 $\mathrm{mV}$ at $0\left[\mathrm{Ca}^{2+}\right]_{\mathrm{i}} ;-75.1 \mathrm{mV}$ and $15.91 \mathrm{mV}$ at $100\left[\mathrm{Ca}^{2+}\right]_{\mathrm{j}}$. C, Po-V relations at 0 (open) and $100 \mu \mathrm{m}$ (filled) $\left[\mathrm{Ca}^{2+}\right]_{\mathrm{i}}$ at negative voltages. $\boldsymbol{D}$, Normalized $\mathrm{Q}-\mathrm{V}$ relations at $0\left[\mathrm{Ca}^{2+}\right]_{\mathrm{i}}$. The smooth curves are fits to Boltzmann function. $\mathrm{V}_{1 / 2}$ and slope factor for E321A/E324A: $190.6 \mathrm{mV}$ and $53.71 \mathrm{mV}$; for E219R/E321A/E324A: $33.8 \mathrm{mV}$ and $46.98 \mathrm{mV}$. the effects of E219R on the opening of the pore in response to voltage sensor movement and $\mathrm{Ca}^{2+}$ binding. Consistent with this idea, E321A/E324A had no effect on Q-V relation (Fig. 3D), further suggesting that the interaction of E321A/E324A with E219 only affected the change in voltage and $\mathrm{Ca}^{2+}$ sensitivity of pore opening but not on gating charge movement.

\section{Mutation E219R alters the coupling} among the activation gate, voltage, and $\mathrm{Ca}^{2+}$ sensors

BK channel gating is an allosteric mechanism that has been described by a model involving voltage sensor activation from the resting state to the activated state $\left((\mathrm{R}-\mathrm{A})_{4}\right.$, for 4 subunits $), \mathrm{Ca}^{2+}$ binding $\left(\left(\mathrm{X}-\mathrm{XCa}^{2+}\right)_{4}\right)$, channel opening $(\mathrm{C}-$ $\mathrm{O})$, and the coupling among these three processes: C-E factors (Horrigan et al., 1999). Here the allosteric $D$ factor quantifies the coupling between voltage sensor activation and pore opening such that the $\mathrm{C}-\mathrm{O}$ equilibrium constant increases $\mathrm{D}$-fold for each voltage sensor activated, and reciprocally, the R-A equilibrium constant increases D-fold when the channel opens. Likewise, the $\mathrm{C}$ factor quantifies the coupling between $\mathrm{Ca}^{2+}$ binding and pore opening, whereas the $\mathrm{E}$ factor quantifies the coupling between $\mathrm{Ca}^{2+}$ binding and voltage sensor activation (Horrigan et al., 1999). To examine which molecular process, the responses of voltage or $\mathrm{Ca}^{2+}$ sensors, the pore opening or the coupling between sensors and the pore, was altered by E219R, we fitted the model to the gating currents (Fig. 1D) and ionic currents of the WT and E219R channels at various voltages and $\left[\mathrm{Ca}^{2+}\right]_{i}$ 's (Fig. 4; Table 2).

The results (Table 2) showed that mutation E219R altered voltage sensor activation by shifting the voltage sensor movement in the closed channel, $V_{h}(J)$, to less positive voltages and increasing gating charge of each voltage sensor, $z_{\text {J }}$. Along with the increase of gating charge associated with pore opening, $Z_{L}$, the total gating charge valence, $\mathrm{z}_{\mathrm{T}}=\mathrm{z}_{\mathrm{L}}+4 \mathrm{z}_{\mathrm{J}}$, was increased by 0.88 . These results reflected the experimentally measured changes in Q-V relation (Fig. $1 B$ ) and the limiting slope measurements (Fig. 4A,B), indicating that E219 is part of S4 that senses membrane voltage during channel gating. The mutation also changed $\mathrm{Ca}^{2+}$ binding affinity, $K_{D}$, by $\sim 25 \%$ and the equilibrium constant of channel opening, $\mathrm{L}_{0}$. However, the most striking changes brought by the mutation in addition to gating charge 
movements were found in the couplings among sensors and the activation gate. The coupling of PGD to VSD was reduced (factor $D$ ) but to $\mathrm{Ca}^{2+}$ binding was increased (factor $C$ ); in addition, the coupling between VSD and $\mathrm{Ca}^{2+}$ binding was also reduced (factor $E$ ). Our experimental results demonstrate that mutation E219R alters VSD movements (Figs. $1 B$ and $3 D$ ), and the interaction between E219R and E321 and E324 results in a shift of the G-V to more positive voltages at $0\left[\mathrm{Ca}^{2+}\right]_{\mathrm{i}}$ (Figs. $1 D$ and $3 A)$ and an increase of $\mathrm{Ca}^{2+}$ sensitivity (Figs. $1 D, F$ and $3 A, C$ ). The results of model fittings illustrate that the interaction between E219R and E321 and E324 primarily alters the coupling among the sensors and activation gate to change voltage and $\mathrm{Ca}^{2+}$ dependence of pore opening. These results are consistent with the BK channel structure because E321 and E324 are located in the linker between S6 and the cytosolic gating ring (C-Linker), proximal to the inner pore (Nimigean et al., 2003; Zhang et al., 2006). In Kv channels, the proximal cytosolic side of S6 is important for the coupling between VSD and PGD (Lu et al., 2001; Long et al., 2005), and previous studies showed that the C-Linker in BK channels is important for the coupling between $\mathrm{Ca}^{2+}$ binding and the opening of the activation gate (Niu et al., 2004).

\section{Residue E219 interacts more strongly with E321/E324 in a neighboring subunit}

BK channels are homotetramers, and each channel is formed by four identical Slo1 subunits. To find whether E219 in S4 interacts with E321/E324 in the same mSlo1 subunit (intrasubunit interaction) or in a neighboring subunit (intersubunit interaction), we performed a series of mRNA mixing experiments, in which different ratios of two mRNA species for WT, E219R, E321A/ E324A, or E219R/E321A/E324A mSlo1 subunits were mixed to express in Xenopus oocytes (Fig. 5). We made two assumptions in these experiments. First, the ratios of expressed different subunit proteins are proportional to the mRNA ratios. Second, interaction in each of four pairs of E219-E321/E324 contributes equally and independently to the total $\mathrm{Ca}^{2+}$ sensitivity of the channel, and a change of interaction in any pair only alters the contribution of that pair to the total $\mathrm{Ca}^{2+}$ sensitivity. The second assumption is consistent with previously proposed allosteric models of BK channel activation (Cui et al., 1997). We first validated these assumptions by mixing mRNAs of the WT and E219R subunits with different ratios and then measuring $\mathrm{Ca}^{2+}$ sensitivity in terms of $\Delta \mathrm{V}_{1 / 2}\left(\Delta \mathrm{V}_{1 / 2 \text {-mix }}\right)$ in response to a $\left[\mathrm{Ca}^{2+}\right]_{\mathrm{i}}$ increase from 0 to $100 \mu \mathrm{M}$, In the channels formed by a mixture of the WT and E219R subunits, each mutant E219R subunit could change $\mathrm{Ca}^{2+}$ sensitivity of only one subunit, either its own subunit or a neighboring subunit depending on whether the E219-E321/E324 interaction was intrasubunit or intersubunit. Based on the two assumptions, the $\Delta \mathrm{V}_{1 / 2 \text {-mix }}$ could also be calculated by the following:

$$
\Delta \mathrm{V}_{1 / 2-\text { mix }}=\left(\mathrm{a} \Delta \mathrm{V}_{1 / 2-\mathrm{WT}}+\Delta \mathrm{V}_{1 / 2-\mathrm{E} 219 \mathrm{R}}\right) /(\mathrm{a}+1)
$$

where a was the ratio of WT:E219R subunit proteins, which differed from the ratio of WT:E219R mRNA (x) with a constant
Table 2. Parameters for HA modeling fitting

\begin{tabular}{llllrrrrr}
\hline Construct & $L_{0}$ & $Z_{L}$ & $Z_{J}$ & $V_{h}(J)$ & $K_{D}$ & \multicolumn{1}{c}{$C$} & \multicolumn{1}{c}{$D$} & $E$ \\
\hline WT $^{*}$ & $9.80 \mathrm{E}-07$ & 0.3 & 0.6 & 150 & 11 & 8 & 25 & 2.4 \\
WT & $3.50 \mathrm{E}-07$ & 0.18 & 0.59 & 159 & 12 & 10 & 44 & 4.2 \\
E219R & $7.5 \mathrm{E}-7$ & 0.62 & 0.70 & 40 & 15 & 35 & 8 & 0.2 \\
\hline
\end{tabular}

*Parameters obtained from Horrigan and Aldrich, 2002.

factor (expression factor: $e, a=e x$ ) possibly because of differences in the translation efficiency of the WT and E219R subunit and inaccuracies in the measurements of mRNA concentrations. $\Delta \mathrm{V}_{1 / 2-\mathrm{WT}}$ and $\Delta \mathrm{V}_{1 / 2-\mathrm{E} 219 \mathrm{R}}$ were obtained from the results in Figure $1 D$. Our measured $\Delta \mathrm{V}_{1 / 2 \text {-mix }}$ could be well fitted to the calculated $\Delta \mathrm{V}_{1 / 2 \mathrm{mix}}$ (Fig. $5 B$ ). Likewise, $\Delta \mathrm{V}_{1 / 2 \text {-mix }}$ from different ratios of WT:E321A/E324A mRNA was also tested, and the measured values could also be well fitted to the calculated $\Delta \mathrm{V}_{1 / 2 \text {-mix }}$ (Fig. $5 B$ ). These results suggested that our two assumptions were valid.

We then examined whether E219R interacted with E321/E324 with intrasubunit or intersubunit interactions by studying $\Delta \mathrm{V}_{1 / 2 \text {-mix }}$ from different ratios of E219R:E321A/E324A mRNA. If the interaction was intrasubunit, each mutation E219R or E321/ E324 would only affect $\Delta V_{1 / 2}$ of the subunit that harbors the mutation, and $\Delta \mathrm{V}_{1 / 2 \text {-mix }}$ could be calculated,

$$
\Delta \mathrm{V}_{1 / 2-\text { mix }}=\left(\mathrm{a} \Delta \mathrm{V}_{1 / 2-\mathrm{E} 219 \mathrm{R}}+\Delta \mathrm{V}_{1 / 2-\mathrm{E} 321 \mathrm{~A} / \mathrm{E} 324 \mathrm{~A}}\right) /(\mathrm{a}+1)
$$

If the interaction was intersubunit, the channels formed by a mix of E219R and E321A/E324A subunits, 5 possible subunits compositions and 6 different subunits arrangements could arise from the mixture (Fig. 5A): 1 E321AE324A 3 E219R (top right), 1 E219R 3 E321AE324A (bottom left), 2 E321AE324A 2 E219R (middle), all 4 E219R (top left), and all 4 E321AE324A (bottom right). We divided each subunit into the membrane-spanning domain and cytoplasmic domain, and used MM (membranespanning domain mutation) for E219R, MW (membranespanning domain WT) for E219, CM (cytoplasmic domain 
A
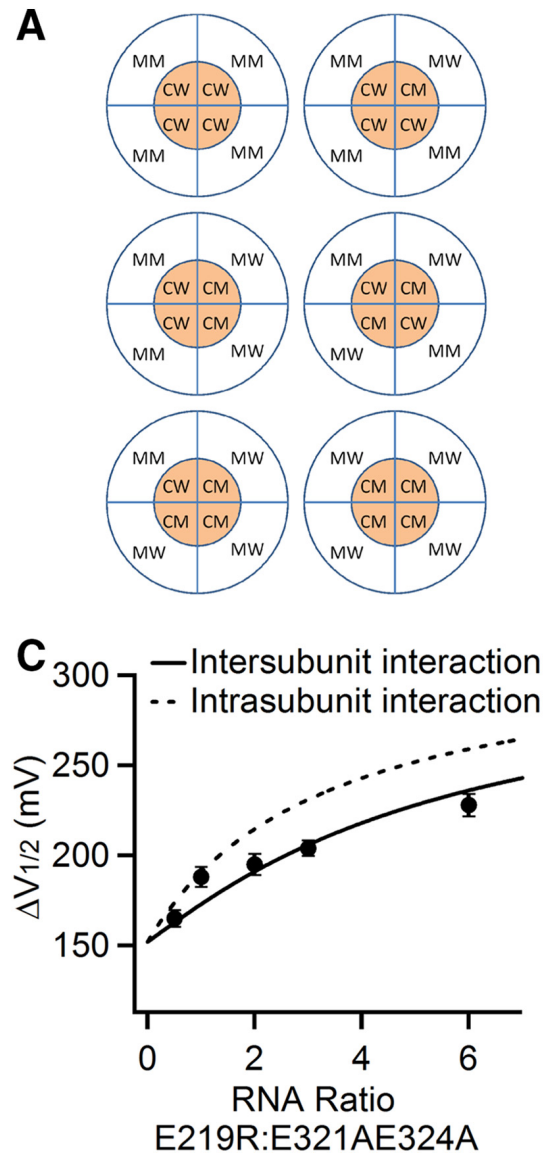

B
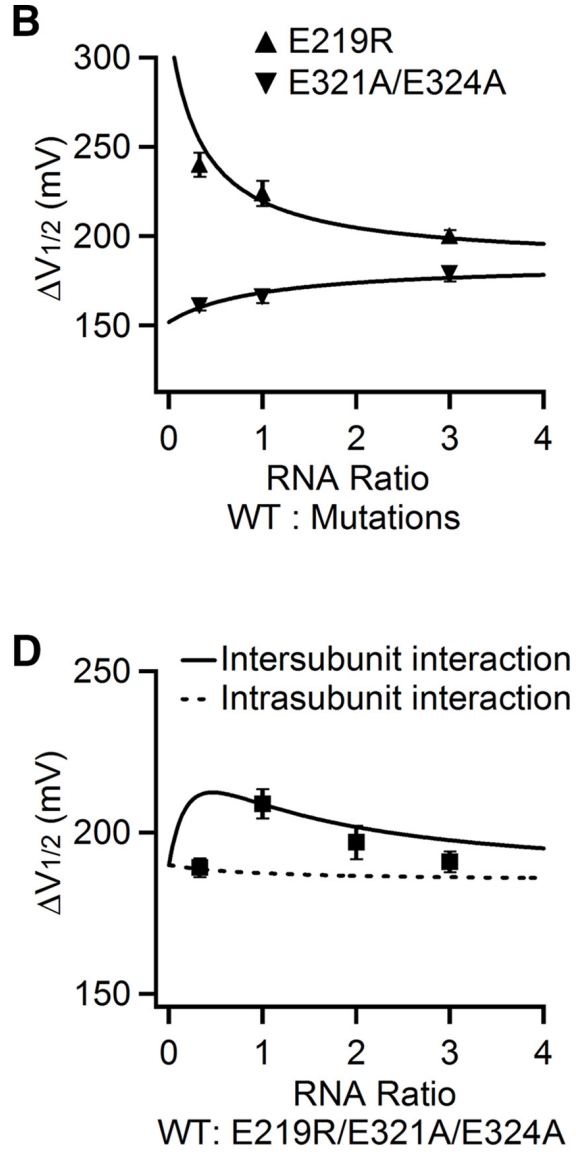

bution of that pair to the total $\mathrm{Ca}^{2+}$ sensitivity. Therefore, if E219 interacted with E321/E324 from a neighboring subunit, the $\mathrm{Ca}^{2+}$ sensitivity, $\Delta \mathrm{V}_{1 / 2 \text {-mix }}$ in response to a $0-100 \mu \mathrm{M}\left[\mathrm{Ca}^{2+}\right]_{\mathrm{i}}$ change, measured from the mixture of all the channels with different subunits compositions would be the weighted average of $\Delta \mathrm{V}_{1 / 2}$ of each subunits composition. For the channels formed by 4 E219R:

$$
\Delta \mathrm{V}_{1 / 2}=\Delta \mathrm{V}_{1 / 2-\mathrm{E} 219 \mathrm{R}}
$$

For the channels formed by 4 E321AE324A:

$$
\Delta \mathrm{V}_{1 / 2}=\Delta \mathrm{V}_{1 / 2-\mathrm{E} 321 \mathrm{AE} 324 \mathrm{~A}}
$$

For the channels formed by 3 E219R 1 E321AE324A, there were two MM-CW interactions, one $\mathrm{MW}-\mathrm{CW}$ interaction, and one MM-CM interaction (Fig. 5A), as follows:

$$
\begin{aligned}
& \Delta \mathrm{V}_{1 / 2}=\left(2 \Delta \mathrm{V}_{1 / 2-\mathrm{E} 219 \mathrm{R}}+\right. \\
& \left.\Delta \mathrm{V}_{1 / 2-\mathrm{WT}}+\Delta \mathrm{V}_{1 / 2-\mathrm{E} 219 \mathrm{RE} 321 \mathrm{AE} 324 \mathrm{~A}}\right) / 4
\end{aligned}
$$

For the channels formed by 1 E219R 3 E321AE324A, there were two MW-CM interactions, one $\mathrm{MW}-\mathrm{CW}$ interaction, and one MM-CM interaction (Fig. 5A), as follows:

$$
\begin{aligned}
\Delta \mathrm{V}_{1 / 2} & =\left(2 \Delta \mathrm{V}_{1 / 2-\mathrm{E} 321 \mathrm{AE} 324 \mathrm{~A}}\right. \\
& \left.+\Delta \mathrm{V}_{1 / 2-\mathrm{WT}}+\Delta \mathrm{V}_{1 / 2-\mathrm{E} 219 \mathrm{RE} 321 \mathrm{AE} 324 \mathrm{~A}}\right) / 4
\end{aligned}
$$
E321/E324. $B, \Delta V_{1 / 2}$ between $\mathrm{G}-\mathrm{V}$ relations at 0 and $100 \mu \mathrm{m}\left[\mathrm{Ca}^{2+}\right]_{\mathrm{i}}$ is plotted versus ratio of mRNA mix of WT with E219R or E321A/E324A. Solid lines are fits to Equation 1 and obtained the expression factor (e) for E219R:WT as 0.30 and for E321A/ E324A:WT as 1.0. $C, \Delta V_{1 / 2}$ is plotted versus ratio of mRNA mix of E219R with E321A/E324A. Solid line is plotted according to Equation 3, whereas the dashed line is plotted according to Equation 2, with the expressing factor obtained from $A$ so that $e$ for E219R:E213A/E324A is 0.30. D, $\Delta V_{1 / 2}$ versus ratio of mRNA mix of WT with E219R/E321A/E324A. Solid line is fit to Equation 3, whereas the dashed line is fit to Equation 2.

mutation) for E321A/E324A, and CW (cytoplasmic domain WT) for E321E324 (Fig. 5A), Therefore, the E219R subunit was presented as $(\mathrm{MM})+(\mathrm{CW})$ and the E321A/E324A subunit was presented as (MW) $+(\mathrm{CM})($ Fig. $5 A)$.

If the ratio of the expressed subunits E219R and E321AE324A was "a," then the possibility for each subunits composition in Figure $5 A$ would be as follows:

$\left\{\mathrm{a}^{4}(4 \mathrm{E} 219 \mathrm{R})\right.$

$$
\begin{gathered}
+4 \mathrm{a}^{3}(3 \mathrm{E} 219 \mathrm{R} 1 \mathrm{E} 321 \mathrm{~A} / \mathrm{E} 324 \mathrm{~A}) \\
+6 \mathrm{a}^{2}(2 \mathrm{E} 219 \mathrm{R} 2 \text { E321A/E324A }) \\
+4 \mathrm{a}(1 \mathrm{E} 219 \mathrm{R} 3 \mathrm{E} 321 \mathrm{~A} / \mathrm{E} 324 \mathrm{~A}) \\
+(4 \mathrm{E} 321 \mathrm{~A} / \mathrm{E} 324 \mathrm{~A})\} /
\end{gathered}
$$

$$
\left(a^{4}+4 a^{3}+6 a^{2}+4 a+1\right)
$$

We have assumed in the main text and validated in Figure $5 B$ that interaction in each of four pairs of E219-E321/E324 contributed equally and independently to the total $\mathrm{Ca}^{2+}$ sensitivity of the channel, and a change of interaction in any pair only altered the contriment, there were one MW-CM interaction, one MM-CM interaction, one MM-CW interaction, and one MM-CM interaction (Fig. $5 A$, middle left), whereas for the diagonal arrangement, there were two MW-CW interactions and two MM-CM interactions (Fig. 5A, middle right). Therefore,

$$
\begin{aligned}
\Delta \mathrm{V}_{1 / 2}=\left(0.5 \Delta \mathrm{V}_{1 / 2-\mathrm{E} 321 \mathrm{AE} 324 \mathrm{~A}}+0.5 \Delta \mathrm{V}_{1 / 2-\mathrm{E} 219 \mathrm{R}}\right. & \\
+ & \left.1.5 \Delta \mathrm{V}_{1 / 2-\mathrm{E} 219 \mathrm{RE} 321 \mathrm{AE} 324 \mathrm{~A}}+1.5 \Delta \mathrm{V}_{1 / 2-\mathrm{WT}}\right) / 4
\end{aligned}
$$

Combined Equations 9-14 and we got the following:

$$
\begin{gathered}
\Delta \mathrm{V}_{1 / 2-\text { mix }}=\left(\mathrm{a}^{4} \Delta \mathrm{V}_{1 / 2-\mathrm{E} 219 \mathrm{R}}+\mathrm{a}^{3}\left(2 \Delta \mathrm{V}_{1 / 2-\mathrm{E} 219 \mathrm{R}}\right.\right. \\
\left.+\Delta \mathrm{V}_{1 / 2-\mathrm{E} 219 \mathrm{R} / \mathrm{E} 321 \mathrm{~A} / \mathrm{E} 324 \mathrm{~A}}+\Delta \mathrm{V}_{1 / 2-\mathrm{WT}}\right) \\
+1.5 \mathrm{a}^{2}\left(1.5 \Delta \mathrm{V}_{1 / 2-\mathrm{E} 219 \mathrm{R} / \mathrm{E} 321 \mathrm{~A} / \mathrm{E} 324 \mathrm{~A}}+1.5 \Delta \mathrm{V}_{1 / 2-\mathrm{WT}}\right. \\
\left.+0.5 \Delta \mathrm{V}_{1 / 2-\mathrm{E} 219 \mathrm{R}}+0.5 \Delta \mathrm{V}_{1 / 2-\mathrm{E} 321 \mathrm{~A} / \mathrm{E} 324 \mathrm{~A}}\right) \\
+\mathrm{a}\left(2 \Delta \mathrm{V}_{1 / 2-\mathrm{E} 321 \mathrm{~A} / \mathrm{E} 324 \mathrm{~A}}+\Delta \mathrm{V}_{1 / 2-\mathrm{E} 219 \mathrm{R} / \mathrm{E} 321 \mathrm{~A} / \mathrm{E} 324 \mathrm{~A}}+\Delta \mathrm{V}_{1 / 2-\mathrm{WT}}\right) \\
\left.+\Delta \mathrm{V}_{1 / 2-\mathrm{E} 321 \mathrm{~A} / \mathrm{E} 324 \mathrm{~A}}\right) /\left(\mathrm{a}^{4}+4 \mathrm{a}^{3}+6 \mathrm{a}^{2}+4 \mathrm{a}+1\right)
\end{gathered}
$$


The calculated $\Delta \mathrm{V}_{1 / 2 \text {-mix }}$ in both cases were plotted in Figure $5 C$ according to Equations 8 and 15, respectively, in which $\Delta \mathrm{V}_{1 / 2-\mathrm{WT}}, \Delta \mathrm{V}_{1 / 2-\mathrm{E} 219 \mathrm{R}}, \Delta \mathrm{V}_{1 / 2-\mathrm{E} 321 \mathrm{~A} / \mathrm{E} 324 \mathrm{~A}}$, and $\Delta \mathrm{V}_{1 / 2-\mathrm{E} 219 \mathrm{R} / \mathrm{E} 321 \mathrm{~A} / \mathrm{E} 324 \mathrm{~A}}$ were obtained by the results in Figures $1 D$ and $3 B$, respectively, and expressing factor (e) for E219R and E321A/E324A was obtained from Figure $5 B$ because the same batch of mRNA was used in these experiments. Our measured $\Delta \mathrm{V}_{1 / 2 \text {-mix }}$ fall on the curve of the intersubunit interactions (Fig. $5 C$ ). Likewise, the same experiment with mixed WT and E219R/E321A/E324A mRNA also supported that E219 interacted with E321/E324 from a neighboring subunit (Fig. 5D). These results make sense intuitively. For instance, in the experiment shown in Figure 5C, the E219R mutation can interact with the E321A/ E324A mutation only with the intersubunit interaction in the E219R and E321A/ E324A subunits mixture. Therefore, it is expected that the increase of $\Delta \mathrm{V}_{1 / 2}$ should be less with intersubunit interaction than with intrasubunit interaction at all E219R: E321A/E324A ratios because E219R increased $\Delta \mathrm{V}_{1 / 2}$ much more when interacting with the WT E321/E324 than with E321A/E324A (Figs. 1 and 3). This expected result is just what we observed in Figure 5C. Likewise, in Figure 5D, the E219R mutation can interact with the WT E321/E324 in the WT and E219R/ E321A/E324A subunits mixture only with the intersubunit interaction. Because $\Delta \mathrm{V}_{1 / 2}$ of E219R/E321A/E324A was similar to that of WT (Figs. 1 and 3 ), the total $\Delta \mathrm{V}_{1 / 2}$ would have been a flat line in the case of intrasubunit interaction at all WT: E219R/ E321A/E324A ratios (Fig. 5D, dotted line). Instead, the experimental data showed a bell-shaped curve (Fig. $5 D$ ), providing a strong evidence that the mutation E219 can interact with the WT E321/E324 in the neighboring WT subunit.

\section{Discussion}

In this study, we found that mutation E219R shifts Q-V relationship leftwards by $126 \mathrm{mV}$ at $0 \mathrm{Ca}^{2+}$ compared with WT and changes slope factor from 50 to $38 \mathrm{mV}$, indicating an increase of gating charge (Fig. $1 A, B$ ). In addition to the direct effects on voltage sensor movements, the mutation also shifts $\mathrm{G}-\mathrm{V}$ relationship rightwards at $0 \mathrm{Ca}^{2+}$ and increases $\mathrm{Ca}^{2+}$ sensitivity (Fig. $1 C-F)$, which are the results of an electrostatic interaction between E219R and E321/E324 (Figs. 2 and 3) that alters the coupling among the activation gate, voltage sensor, and $\mathrm{Ca}^{2+}$ binding (Fig. 4; Table 2).

Ion channels often contain distinct structural domains for sensing physiological stimuli and the pore-activation gate. The coupling among these domains during channel activation is an important molecular process that has not been fully understood. One basic question is as follows: what kind of changes in the properties of channel function would indicate a change of coupling? It has been elegantly shown that, in voltage-gated ion channels, if a mutation only reduces the coupling between the voltage sensor and the pore-gate, an opposite shift in the voltage dependence of charge movement ( $\mathrm{Q}-\mathrm{V}$ relation) and channel opening (G-V relation) would be observed (Chowdhury and Chanda,
S4

S5

SIKLVNLISIFIST-WLTAAGFI HLVE (257) BILFLNIL-K--TSN---SIRLVNLLSIFIST-WLTAAGFIHLVE (257) RHSKGLQILGR-- TLKA--SMRELGLLIF FLFIGVVLFSAVYFAE ( 17$)$ ALSRFEGMRVVVNALLGATPS IMNVLLVCL IFWL I FS IMGVNLFA (1176)

S6 C-Linker

VPEIIELI-GNRKKYGG ( 334 ) SHAKER (451)VGVWGKIVGSLCAIAGVLTIALPVPVIVSNFNYFYMHRETD $(490)$ CHIMERA (379) TTIGGKIVGSLCAIAGVITIALPVPVIVSNFNYFYHRETE (418)
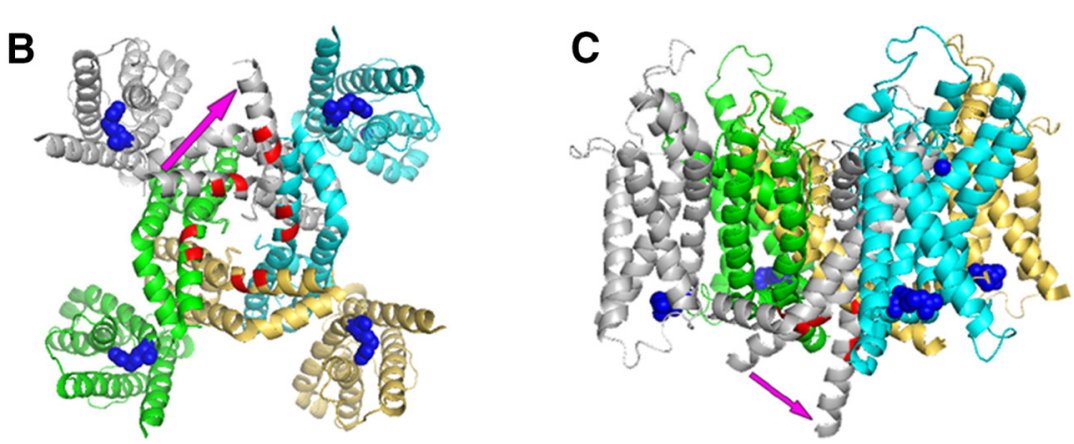

Figure 6. A structure model of BK channels. A, Sequence alignment of BK, shaker (Batulan et al., 2010), Kv1.2/Kv2.1 chimera channels (Long et al., 2007), and sodium NAV1.4 channel domain III (Muroi et al., 2010). Purple represents residues that interact ,2007). Blue spheres represent residues corresponding to E219R in mSlo1; red represents the main chain of residues correspond.

2012). Our result that at $0\left[\mathrm{Ca}^{2+}\right]_{\mathrm{i}}$ E219R shifts the Q-V relation to more negative voltages, and the $\mathrm{G}-\mathrm{V}$ relation to more positive voltages seems to immediately indicate a reduction in the coupling between the voltage sensor and the activation gate. However, two observations prevent us from reaching this conclusion simply by this result. First, E219R alters not only the voltage range but also the slope of the Q-V relation (Fig. 1B), and the mutation also changes the limiting slope of Po- $\mathrm{V}$ at negative voltages (Fig. $4 B$ ), suggesting a direct change in the gating charge in addition to the possible change of coupling. The mutation E321A/E324A almost abolished the effect at $0\left[\mathrm{Ca}^{2+}\right]_{\mathrm{i}}$ of E219R in shifting the G-V relation (Fig. 3A) but not the Q-V relation (Fig. 3D), supporting that the shift of $\mathrm{Q}-\mathrm{V}$ and $\mathrm{G}-\mathrm{V}$ relations may derive from different mechanisms. Second, E219R shifts the G-V relation to more positive voltages at $0\left[\mathrm{Ca}^{2+}\right]_{\mathrm{i}}$ but to more negative voltages at $100 \mu \mathrm{M}\left[\mathrm{Ca}^{2+}\right]_{\mathrm{i}}$ (Fig. 1D). Therefore, as far as the voltagedependent gating of the channels at $100 \mu \mathrm{M}\left[\mathrm{Ca}^{2+}\right]_{\mathrm{i}}$ is concerned, the relation between $\mathrm{Q}-\mathrm{V}$ and $\mathrm{G}-\mathrm{V}$ does not indicate a reduction in the coupling between the voltage sensor and activation gate. BK channel gating can be described by the HA allosteric model, in which the couplings between the activation gate with the voltage sensor and $\mathrm{Ca}^{2+}$ binding are explicitly and quantitatively defined (Horrigan and Aldrich, 2002). The fitting of the HA model to our experimental data shows that mutation E219R reduces the coupling between the activation gate with the voltage sensor but increases the coupling with $\mathrm{Ca}^{2+}$ binding (Fig. 4; Table 2). In addition, the model fitting also revealed that the coupling between the voltage sensor and $\mathrm{Ca}^{2+}$ binding is also reduced by E219R.

The location of E219 in the cytosolic end of S4 and E321/E324 in the cytosolic C-linker is consistent with the results that the electrostatic interactions among these residues alter the coupling between the activation gate and the voltage and $\mathrm{Ca}^{2+}$ sensors. It has been shown that, in BK channels, the shortening or length- 
ening of the C-Linker, which connects to the cytosolic gating ring (Wu et al., 2010; Yuan et al., 2010, 2011), alters voltage and $\mathrm{Ca}^{2+}$ dependence of channel gating (Niu et al., 2004). Because the gating ring contains two $\mathrm{Ca}^{2+}$ binding sites (Schreiber and Salkoff, 1997; Shi et al., 2002; Xia et al., 2002; Yuan et al., 2010; Zhang et al., 2010), these results suggested that the C-Linker plays an important role in coupling between the activation gate and $\mathrm{Ca}^{2+}$ sensors. The fact that $\mathrm{Ca}^{2+}$ sensitivity derived from either $\mathrm{Ca}^{2+}$ binding site is increased by E219R (Table 1) further supports the suggestion that the mutation increases $\mathrm{Ca}^{2+}$ sensitivity by enhancing the coupling. In Kv channels, the interactions between the S4-S5 linker and the cytosolic side of S6 are important for the coupling between the voltage sensor and the activation gate (Lu et al., 2001; Tristani-Firouzi et al., 2002). Other locations where the VSD and PD may make contacts, such as the S4 and S5 helices (Ledwell and Aldrich, 1999; Soler-Llavina et al., 2006; Grabe et al., 2007) and the extracellular side of the $S 1$ and the pore helix (Lee and Cui, 2009), are also implicated in coupling. In voltage-gated $\mathrm{Na}^{+}$channels, the interaction between the S4-S5 linker and the cytosolic side of S6 is also suggested as important for the coupling (Muroi et al., 2010). However, our results suggest that the C-Linker in BK channels may orient to a direction that differs from that in $\mathrm{Kv}$ channels (Fig. 6). Therefore, the interaction between C-Linker and the S4-S5 linker may be eliminated or modulated in BK channels.

Our experimental results suggest that E219R interacts with E321/E324 in a neighboring subunit (Fig. 5). This result highlights a difference between BK channels and $\mathrm{Kv}$ (Batulan et al., 2010) or Nav (Muroi et al., 2010) channels, in which the residues interacting with neighboring subunits are located at the beginning of S5 (Fig. 6A). We labeled the residues in the structure of Kv1.2/Kv2.1 chimera channel (Long et al., 2007) equivalent to E219R and E321/E324 of mSlo1 and found that E321/E324 are located far from E219R either within the same subunit or in the neighboring subunit (Fig. 6B). If we assume that the $\mathrm{S} 6$ of mSlo1 bends to orient differently from that in Kv1.2 (Fig. 6B), our experimentally observed intersubunit interaction between E219R and E321/E324 can be explained. Such a structural difference can also account for two other unique properties of BK channels. First, in a previous study, we showed that residues from the membrane-spanning domain of one subunit and residues from the cytosolic domain of a neighboring subunit form the $\mathrm{Mg}^{2+}$ binding site for channel activation, which cannot be explained if the membrane-spanning domain of BK channels adopts a structure similar to that of Kv1.2 (Yang et al., 2008). Our proposed orientation of the $\mathrm{S} 6$ segment (Fig. $6 B, C$ ) is consistent with this result such that the cytosolic domain of one subunit can align with the membrane-spanning voltage sensor of the neighboring subunit. Second, the studies of channel blocking by quaternary ammonium suggested that the inner pore of BK channels allows the entry of large quaternary ammonium molecules when the channel is closed so that the inner pore formed by the bottom of S6 helices differs from that of Kv channels and does not restrict the permeation of ions or quaternary ammonium molecules ( $\mathrm{Li}$ and Aldrich, 2004; Wilkens and Aldrich, 2006; Tang et al., 2009). S6 with a similar bending as suggested (Fig. $6 B, C$ ) would enlarge the inner pore and not able to restrict permeation of ions even when the channel is closed.

The interaction between E219R and E321/E324 resulted in large changes of BK channel activation (Fig. 1). The neutralization of E219, such as E219Q, also altered BK channel activation significantly (Fig. 2A). These results suggest that, in the WT BK channels, the electrostatic interaction between E219 and E321/
E324 contributes to voltage and $\mathrm{Ca}^{2+}$-dependent activation by participating in the coupling among the pore and the sensors, although compared with the effects of E219R, which increased $\mathrm{Ca}^{2+}$ sensitivity $\left(\Delta \mathrm{V}_{1 / 2}\right)$ by $>50 \%$, the effects of $\mathrm{E} 219 \mathrm{Q}$ are much smaller. It will be interesting for future studies to understand how the electrostatic attraction between E219R and E321/E324 alters the coupling among the pore and the sensors.

\section{References}

Bao L, Kaldany C, Holmstrand EC, Cox DH (2004) Mapping the BKCa channel's " $\mathrm{Ca}^{2+}$ bowl": side-chains essential for $\mathrm{Ca}^{2+}$ sensing. J Gen Physiol 123:475-489. CrossRef Medline

Batulan Z, Haddad GA, Blunck R (2010) An intersubunit interaction between S4-S5 linker and S6 is responsible for the slow off-gating component in shaker K+ channels. J Biol Chem 285:14005-14019. CrossRef Medline

Bezanilla F (2005) Voltage-gated ion channels. IEEE Trans Nanobiosci 4:34-48. CrossRef

Brayden JE, Nelson MT (1992) Regulation of arterial tone by activation of calcium-dependent potassium channels. Science 256:532-535. CrossRef Medline

Butler A, Tsunoda S, McCobb DP, Wei A, Salkoff L (1993) mSlo, a complex mouse gene encoding "maxi" calcium-activated potassium channels. Science 261:221-224. CrossRef Medline

Chowdhury S, Chanda B (2012) Thermodynamics of electromechanical coupling in voltage-gated ion channels. J Gen Physiol 140:613-623. CrossRef Medline

Cui J, Aldrich RW (2000) Allosteric linkage between voltage and $\mathrm{Ca}^{2+}$ dependent activation of BK-type mslo1 $\mathrm{K}^{+}$channels. Biochemistry 39: 15612-15619. CrossRef Medline

Cui J, Cox DH, Aldrich RW (1997) Intrinsic voltage dependence and $\mathrm{Ca}^{2+}$ regulation of mslo large conductance Ca-activated $\mathrm{K}^{+}$channels. J Gen Physiol 109:647-673. CrossRef Medline

Cui J, Yang H, Lee U (2009) Molecular mechanisms of BK channel activation. Cell Mol Life Sci 66:852-875. CrossRef Medline

Grabe M, Lai HC, Jain M, Nung Jan YN, Jan LY (2007) Structure prediction for the down state of a potassium channel voltage sensor. Nature 445: 550-553. CrossRef Medline

Horrigan FT, Aldrich RW (2002) Coupling between voltage sensor activation, $\mathrm{Ca}^{2+}$ binding and channel opening in large conductance (BK) potassium channels. J Gen Physiol 120:267-305. CrossRef Medline

Horrigan FT, Cui J, Aldrich RW (1999) Allosteric voltage gating of potassium channels I. Mslo ionic currents in the absence of $\mathrm{Ca}^{2+}$. J Gen Physiol 114:277-304. CrossRef Medline

Hu L, Shi J, Ma Z, Krishnamoorthy G, Sieling F, Zhang G, Horrigan FT, Cui J (2003) Participation of the $S 4$ voltage sensor in the $\mathrm{Mg}^{2+}$-dependent activation of large conductance (BK) $\mathrm{K}^{+}$channels. Proc Natl Acad Sci U S A 100:10488-10493. CrossRef Medline

Lancaster B, Nicoll RA (1987) Properties of two calcium-activated hyperpolarizations in rat hippocampal neurones. J Physiol 389:187-203. Medline

Ledwell JL, Aldrich RW (1999) Mutations in the S4 region isolate the final voltage-dependent cooperative step in potassium channel activation. J Gen Physiol 113:389-414. CrossRef Medline

Lee US, Cui J (2009) $\beta$ subunit-specific modulations of BK channel function by a mutation associated with epilepsy and dyskinesia. J Physiol 587: 1481-1498. CrossRef Medline

Li W, Aldrich RW (2004) Unique inner pore properties of BK channels revealed by quaternary ammonium block. J Gen Physiol 124:43-57. CrossRef Medline

Long SB, Campbell EB, Mackinnon R (2005) Voltage sensor of Kv1.2: structural basis of electromechanical coupling. Science 309:903-908. CrossRef Medline

Long SB, Tao X, Campbell EB, MacKinnon R (2007) Atomic structure of a voltage-dependent $\mathrm{K}^{+}$channel in a lipid membrane-like environment. Nature 450:376-382. CrossRef Medline

Lu Z, Klem AM, Ramu Y (2001) Ion conduction pore is conserved among potassium channels. Nature 413:809-813. CrossRef Medline

Muroi Y, Arcisio-Miranda M, Chowdhury S, Chanda B (2010) Molecular determinants of coupling between the domain III voltage sensor and pore of a sodium channel. Nat Struct Mol Biol 17:230-237. CrossRef Medline

Nimigean CM, Chappie JS, Miller C (2003) Electrostatic tuning of ion conductance in potassium channels. Biochemistry 42:9263-9268. CrossRef Medline 
Niu X, Qian X, Magleby KL (2004) Linker-gating ring complex as passive spring and $\mathrm{Ca}^{2+}$-dependent machine for a voltage- and $\mathrm{Ca}^{2+}$-activated potassium channel. Neuron 42:745-756. CrossRef Medline

Robitaille R, Garcia ML, Kaczorowski GJ, Charlton MP (1993) Functional colocalization of calcium and calcium-gated potassium channels in control of transmitter release. Neuron 11:645-655. CrossRef Medline

Schreiber M, Salkoff L (1997) A novel calcium-sensing domain in the BK channel. Biophys J 73:1355-1363. CrossRef Medline

Shi J, Krishnamoorthy G, Yang Y, Hu L, Chaturvedi N, Harilal D, Qin J, Cui J (2002) Mechanism of magnesium activation of calcium-activated potassium channels. Nature 418:876-880. CrossRef Medline

Soler-Llavina GJ, Chang TH, Swartz KJ (2006) Functional interactions at the interface between boltage-sensing and pore domains in the shaker $\mathrm{Kv}$ channel. Neuron 52:623-634. CrossRef Medline

Storm JF (1987) Action potential repolarization and a fast after-hyperpolarization in rat hippocampal pyramidal cells. J Physiol 385:733-759. Medline

Tang QY, Zeng XH, Lingle CJ (2009) Closed-channel block of BK potassium channels by bbTBA requires partial activation. J Gen Physiol 134: 409-436. CrossRef Medline

Tristani-Firouzi M, Chen J, Sanguinetti MC (2002) Interactions between S4-S5 linker and S6 transmembrane domain modulate gating of HERG $\mathrm{K}^{+}$channels. J Biol Chem 277:18994-19000. CrossRef Medline

Wang L, Sigworth FJ (2009) Structure of the BK potassium channel in a lipid membrane from electron cryomicroscopy. Nature 461:292-295. CrossRef Medline

Wilkens CM, Aldrich RW (2006) State-independent block of BK channels by an intracellular quaternary ammonium. J Gen Physiol 128:347-364. CrossRef Medline
Wu Y, Yang Y, Ye S, Jiang Y (2010) Structure of the gating ring from the human large-conductance $\mathrm{Ca}^{2+}$-gated $\mathrm{K}^{+}$channel. Nature 466:393-397. CrossRef Medline

Xia XM, Zeng X, Lingle CJ (2002) Multiple regulatory sites in largeconductance calcium-activated potassium channels. Nature 418:880884. CrossRef Medline

Yang H, Hu L, Shi J, Delaloye K, Horrigan FT, Cui J (2007) $\mathrm{Mg}^{2+}$ mediates interaction between the voltage sensor and cytosolic domain to activate BK channels. Proc Natl Acad Sci U S A 104:18270-18275. CrossRef Medline

Yang H, Shi J, Zhang G, Yang J, Delaloye K, Cui J (2008) Activation of Slo1 BK channels by $\mathrm{Mg}^{2+}$ coordinated between the voltage sensor and RCK1 domains. Nat Struct Mol Biol 15:1152-1159. CrossRef Medline

Yellen G (1998) The moving parts of voltage-gated ion channels. Q Rev Biophys 31:239-295. CrossRef Medline

Yuan P, Leonetti MD, Pico AR, Hsiung Y, MacKinnon R (2010) Structure of the human $\mathrm{BK}$ channel $\mathrm{Ca}^{2+}$-activation apparatus at 3.0 A resolution. Science 329:182-186. CrossRef Medline

Yuan P, Leonetti MD, Hsiung Y, MacKinnon R (2011) Open structure of the $\mathrm{Ca}^{2+}$ gating ring in the high-conductance $\mathrm{Ca}^{2+}$-activated $\mathrm{K}^{+}$channel. Nature 481:94-97. CrossRef Medline

Zhang G, Huang SY, Yang J, Shi J, Yang X, Moller A, Zou X, Cui J (2010) Ion sensing in the RCK1 domain of BK channels. Proc Natl Acad Sci U S A 107:18700-18705. CrossRef Medline

Zhang Z, Zhou Y, Ding JP, Xia XM, Lingle CJ (2006) A limited access compartment between the pore domain and cytosolic domain of the BK channel. J Neurosci 26:11833-11843. CrossRef Medline 